\title{
Safety of hydroxychloroquine in COVID-19 and other diseases: a systematic review and meta-analysis of 53 randomized trials
}

\section{Can Chen ${ }^{1} \cdot$ Kunming Pan ${ }^{1} \cdot$ Bingjie $\mathrm{Wu}^{2} \cdot$ Xiaoye $\mathrm{Li}^{1} \cdot$ Zhangzhang Chen $^{1} \cdot$ Qing Xu ${ }^{1} \cdot$ Xiaoyu Li ${ }^{1} \cdot$ Qianzhou $\mathrm{Lv}^{1}$ (D)}

Received: 28 April 2020 / Accepted: 15 July 2020 / Published online: 11 August 2020

(C) Springer-Verlag GmbH Germany, part of Springer Nature 2020

\begin{abstract}
Introduction Many concerns still exist regarding the safety of hydroxychloroquine (HCQ) in the treatment of Coronavirus Disease 2019 (COVID-19).

Objectives The purpose of this study was to evaluate the safety of HCQ in the treatment of COVID-19 and other diseases by performing a systematic review and meta-analysis.

Methods Randomized controlled trials (RCTs) reporting the safety of HCQ in PubMed, Embase, and Cochrane Library were retrieved starting from the establishment of the database till June 5, 2020. Literature screening, data extraction, and assessment of risk bias were performed independently by two reviewers.

Results We identified 53 eligible studies involving 5496 patients. The meta-analysis indicated that the risk of adverse effects (AEs) in the HCQ group was significantly increased compared with that in the control group (RD $0.05,95 \% \mathrm{CI}, 0.02$ to $0.07, P=$ 0.0002), and the difference was also statistically significant in the COVID-19 subgroup (RD 0.15, 95\%CI, 0.07 to $0.23, P=$ 0.0002 ) as well as in the subgroup for other diseases (RD $0.03,95 \% \mathrm{CI}, 0.01$ to $0.04, P=0.003$ ).

Conclusions HCQ is associated with a high total risk of AEs compared with the placebo or no intervention in the overall population. Given the small number of COVID-19 participants included, we should be cautious regarding the conclusion stating that HCQ is linked with an increase incidence of AEs in patients with COVID-19, which we hope to confirm in the future through well-designed and larger sample size studies.
\end{abstract}

Keywords Hydroxychloroquine $\cdot$ Safety $\cdot$ Randomized controlled trial $\cdot$ Systematic review $\cdot$ COVID-19

\section{Introduction}

Even though the war against COVID-19 in China has ushered in the dawn, the global pandemic has become more overwhelming in other parts of the world. Chloroquine, which is widely known

Can Chen and Kunming Pan contributed equally to this work.

Electronic supplementary material The online version of this article (https://doi.org/10.1007/s00228-020-02962-5) contains supplementary material, which is available to authorized users.

Xiaoyu Li

li.xiaoyu@zs-hospital.sh.cn

Qianzhou Lv

lv.qianzhou@zs-hospital.sh.cn

1 Department of Pharmacy, Zhongshan Hospital, Fudan University, Shanghai 200032, China

2 Department of Rheumatology, Zhongshan Hospital, Fudan University, Shanghai 200032, China and used both as an antimalarial and a disease-modifying antirheumatic drug (DMARD) in autoimmunity conditions, has also been reported as a potential broad-spectrum antiviral drug in previous articles. A recent study demonstrated that chloroquine is effective against SARS-CoV-2 in vitro [1]; thus, it was incorporated into antiviral treatment options in the sixth [2] and seventh trial editions of China's protocol against COVID-19 [3]. As a derivative of chloroquine, HCQ has a similar antiviral mechanism, but it is well tolerated [4-6]. The adverse reactions (ADRs) associated with HCQ involve various systemic organs, among which irreversible retinopathy is of highest concern. Previous studies pointed out that the overall prevalence rate of patients receiving HCQ for more than 5 years is $7.5 \%$, which may rise to roughly $20 \% 20$ years later [7]. Other frequently reported SAEs mostly consisted of cardiotoxicities such as cardiomyopathy [8-11], and cutaneous toxicities such as acute generalized exanthematous pustulosis [12-14], pigmentation [15-17], and toxic epidermal necrolysis $[18,19]$. To date, a series of studies on HCQ use against COVID-19 have been published, but there 
remain many controversies regarding its efficacy and safety. This study aims to investigate the incidence of the AEs caused by HCQ in RCTs on COVID-19 and other diseases, and eventually to provide evidence for safe COVID-19 therapy.

\section{Methods}

We conducted the study following the Preferred Reporting Items for Systematic Review and Meta-Analyses (PRISMA) guidelines [20]. The study protocol was registered in PROSPERO (CRD42020176407).

\section{Search strategy}

RCTs published in English and Chinese were searched systematically in PubMed, Embase, and Cochrane Library up to June 5, 2020. The Medical Subject Headings "hydroxychloroquine" and free text words such as "hydroxychloroquine," "random," "randomization," "randomized," "randomized," "randomly" were combined with the Boolean operator "AND" and "OR". See Tables S1-3 for detailed retrieval strategies. We also browsed medRxiv for new studies up to the submission date. Additionally, references cited in the articles were checked for and found to be available.

\section{Study selection}

We had access to all the publications that evaluated the safety of HCQ, including RCTs enrolling adult patients, published in English and Chinese. We excluded studies with unavailable full texts, as well as studies that were not published as RCTs, and also those involving children, not reporting the safety outcomes, and focusing on other irrelevant topics. The primary outcome was the total AEs, and the secondary outcomes were the gastrointestinal AEs, skin and subcutaneous tissue AEs, ophthalmic AEs, cardiac AEs, treatment discontinuation caused by AEs, and total SAEs. AEs were defined as any undesirable experience associated with the use of a medical product in a patient, and SAEs were defined as fatal, lifethreatening, requiring hospitalization (initial or prolonged), causing disability or permanent damage, or congenital anomaly/birth defect, or required intervention to prevent permanent impairment or damage (devices) [21]. The literature selection was performed independently by two researchers (C.C and KM.P), and any disagreements were solved through discussion or seeking the advice of another reviewer.

\section{Data extraction}

Two researchers (C.C and KM.P) extracted the data of the eligible studies independently, including information on the authors, year of publication, country, region, study type, study population, age, HCQ dosage, follow-up time, and the occurrence of AEs and SAEs. We aggregated all the recorded specific AEs according to the system organs classification in the Medical Dictionary for Regulatory Activities (MedDRA), and if the specific AEs were not available, we used data recorded according to the system organs classification [22]. The recorded data were cross-checked by two researchers (C.C and KM.P), and if a consensus regarding the inconsistencies could not be reached, another reviewer would participate in the decision. For studies that covered two intervention groups, we merged the two intervention groups into one for analysis [23].

\section{Risk of bias assessment}

The risks of bias in the eligible studies were assessed using the Cochrane Collaboration's tool for assessing risk of bias in randomized trials [24], which were comprised of the following seven domains: random sequence generation, allocation concealment, blinding of participants and personnel, blinding of outcome assessment, incomplete outcome data, selective reporting, and anything else. High-quality studies were defined as studies with low risk of bias in key domains such as random sequence generation, blinding of participants and outcome assessment, incomplete outcome data, and selective reporting.

\section{Statistical analysis}

We conducted the meta-analysis using Review Manager 5.3.5 software [25]. The risk difference (RD) and 95\% confidence interval (CI) for the risks of AEs between the HCQ group and control group were calculated. We used the $\chi^{2}$ test for exploration of the heterogeneity, and $\mathrm{I}^{2}$ statistics were applied to quantify the heterogeneity. The random-effect model was used for quantitative synthesis. Furthermore, funnel plots were selected to assess the risk of publication bias for the outcomes reported by nine or more studies. The subgroup analyses were performed for AEs based on the diagnosis and the daily doses of HCQ. We considered daily doses exceeding $400 \mathrm{mg}$ as the high dosage group, and those lower than $400 \mathrm{mg}$ as the standard dosage group. Sensitivity analyses were carried out by changing the type of effect model, eliminating literature one by one, while meta-analyses were performed exclusively for high-quality studies.

\section{Results}

\section{Literature search}

A total of 2524 articles were identified, out of which 184 studies were potentially eligible, and 53 RCTs [26-78] published in English and Chinese between 1976 and 2020 were finally included after the title/abstract and full-text screening 
process. The PRISMA 2009 flow diagram of literature screening is illustrated Fig. 1.

\section{Characteristics and risk bias of the eligible studies}

Among the 5496 patients enrolled in those 53 studies [26-78], 2831 patients received HCQ and 2665 received a placebo or no treatment at all. The included subjects were from 18 countries with a mean or median age of 29 to 78 years old. Four studies [26, 60, 61, 63] were carried out in COVID-19 patients, whereas the remaining 49 $[27-59,62,64-78]$ were focused on other diseases. HCQ was administered in seven of the eligible studies [33, 63,
75-77] for disease prophylaxis, and the remaining studies reported administration for therapeutic use. Thirty-eight of the eligible studies were placebo-controlled, while 15 studies $[26,34,36,41,60-62,64,66,68,70,75]$ stated that no intervention was given to participants in the control group. The daily dosages of HCQ used in ten studies [34, 36, 37, $45,47,61,63,69,75,76]$ exceeded $400 \mathrm{mg}$, and the maximum dosage was $1200 \mathrm{mg}$ once daily [36, 47]. The followup times ranged from 6 days to 40 months across studies, and most studies reported follow ups of less than 12 months $[26-29,31-33,35-46,49,50,52,55-58,60,61,63-65,67$, 69-78]. The basic characteristics of the included studies are presented in Table S4.

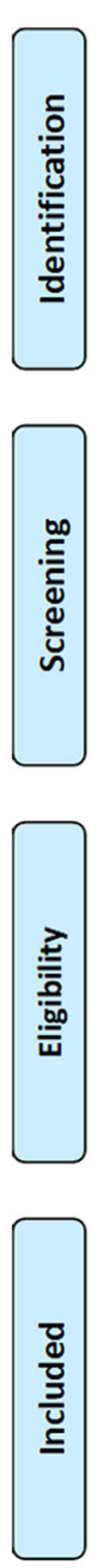

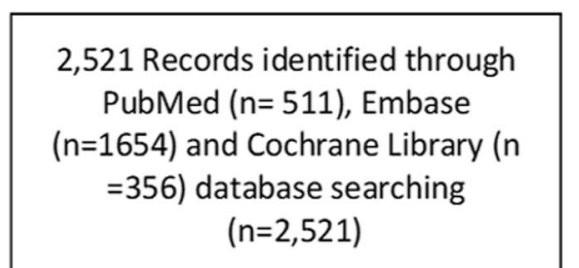

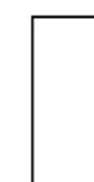

Additional records identified through other sources $(n=3)$

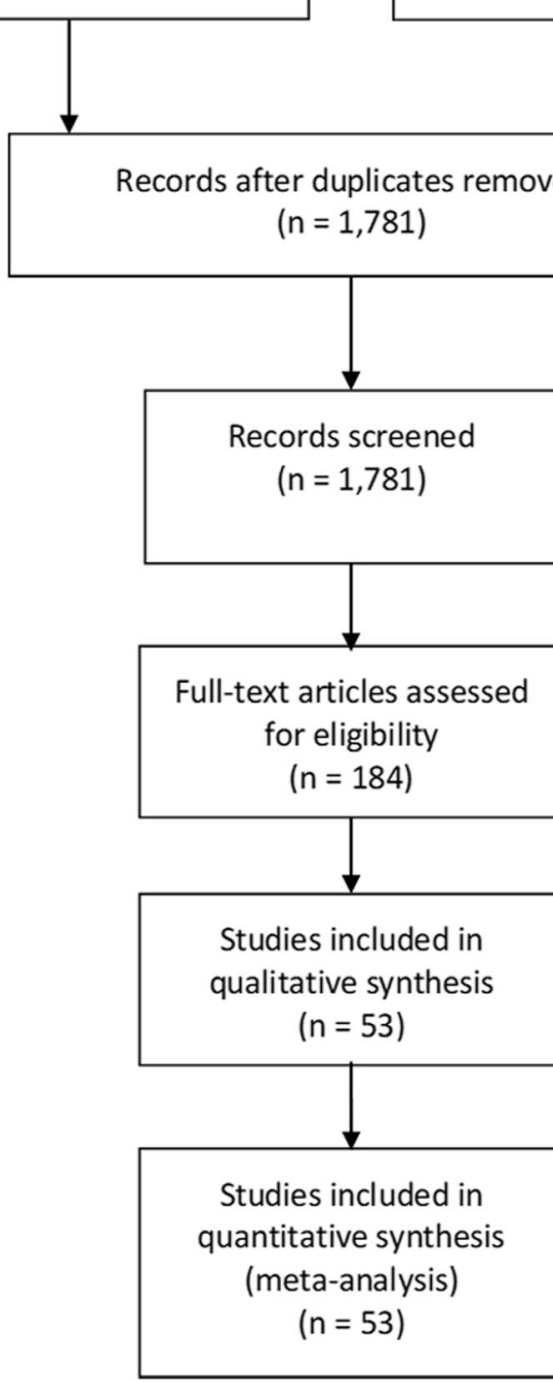

Records excluded $(n=1,597)$

Wrong population $n=51$

Wrong interventions $n=519$

Wrong comparators $n=151$

No safety outcome reported $n=114$

Wrong type of studies $n=742$

Duplicated of other studies $n=20$

Full-text articles excluded, with

reasons $(n=131)$

Wrong population $n=2$

Wrong interventions $n=2$

Wrong comparators $n=15$

No safety outcome reported $n=9$

Wrong type of studies $n=6$

Duplicated of other studies $n=17$

Ongoing studies without results $n=71$

Full texts were unavailable $n=9$

Fig. 1 The PRISMA 2009 flow diagram in literature screening 
Nearly $30 \%$ of the studies did not specify the generation of random sequences, and $70 \%$ did not state or use the allocation concealment. Based on this fact, a high risk of selection bias might exist in these studies. Approximately $30 \%$ of the studies had a high risk of participants or outcomes assessment blinding. Most of the studies had low attrition and reporting biases. Of the 53 studies, 19 [30-33, 37-40, 42-44, 46, 50, 51, $53,56,57,63,78]$ were considered high-quality studies with low risk of bias in key domains. Risks of bias assessment of all the eligible studies are presented in Fig. S1-2.

\section{Outcome Measures}

\section{AEs}

Forty-four studies (4 in COVID-19 patients and 40 in patients with other diseases) $[26-35,37-42,44-47,49-51,53-66,70$, 72, 73, 75-78] reported their total AEs, with 698 and 431 AEs reported in the HCQ group and control group, respectively. The meta-analysis demonstrated that the risk of AEs in the HCQ group was significantly higher compared with the control group's (RD $0.05,95 \% \mathrm{CI}, 0.02$ to $0.07, P=0.0002, \mathrm{I}^{2}=$ $62 \%$ ), and the difference was statistically significant in the COVID-19 subgroup (RD $0.15,95 \% \mathrm{CI}, 0.07$ to $0.23, P=$ $0.0002, \mathrm{I}^{2}=48 \%$ ) and other diseases subgroup (RD 0.03, $95 \% \mathrm{CI}, 0.01$ to $0.04, P=0.003, \mathrm{I}^{2}=15 \%$ ) (Fig. 2 ). The subgroup analysis based on the daily dosage of HCQ suggested that, in high dosage subgroups, the risk of AEs was statistically different (RD 0.19, 95\%CI, 0.14 to $0.24, P<0.00001, \mathrm{I}^{2}=0 \%$ ) in COVID-19 patients and not different in other diseases (RD $0.01,95 \% \mathrm{CI},-0.03$ to $0.05, P=0.62, \mathrm{I}^{2}=13 \%$ ) between the HCQ and control groups. However, in low dosage subgroups, the differences did not reach a statistical significance in COVID-19 patients (RD $0.06,95 \% \mathrm{CI},-0.03$ to $0.16, P=$ $0.19, \mathrm{I}^{2}=0 \%$ ), meanwhile these differences were significant in other diseases (RD $0.03,95 \% \mathrm{CI}, 0.01$ to $0.05, P=0.002$, $\left.\mathrm{I}^{2}=18 \%\right)$.

\section{Gastrointestinal AEs}

Two studies [26, 61] conducted in COVID-19 patients and 30 studies [27-30, 32, 34, 36, 37, 39, 40, 42, 43, 45, 47, 49, 50, $53,54,57-59,62,64-66,69,70,75,77,78]$ in other diseases reported gastrointestinal AEs. The incidence of gastrointestinal AEs in the HCQ group was significantly higher than that in the control group (RD $0.03,95 \% \mathrm{CI}, 0.01$ to $0.06, P=0.02$, $\mathrm{I}^{2}=55 \%$ ). The risks of developing gastrointestinal AEs were both increased in the COVID-19 subgroup (RD 0.11, 95\%CI, 0.04 to $0.19, P=0.003, \mathrm{I}^{2}=0 \%$ ) and the subgroup for other diseases (RD $0.03,95 \% \mathrm{CI}, 0.00$ to $0.05, P=0.04, \mathrm{I}^{2}=50 \%$ ) (Fig. S3).

\section{Skin and subcutaneous tissue AEs}

Three studies $[60,61,63]$ in COVID-19 patients and 25 studies $[29,32,33,35,37-40,43-46,49,54,56,58,59,64,66$, $70,75,77]$ in patients with other diseases reported skin and subcutaneous tissue AEs. Similarly, the risk of skin and subcutaneous tissue AEs in the HCQ group was significantly different from that in the control group (RD 0.02, 95\% CI, 0.00 to $0.03, P=0.02, \mathrm{I}^{2}=25 \%$ ). Furthermore, the metaanalysis results of the studies performed in patients with other diseases were consistent with the overall observations (RD $0.02,95 \% \mathrm{CI}, 0.00$ to $0.04, P=0.03, \mathrm{I}^{2}=20 \%$ ). The metaanalysis of the studies carried out in COVID-19 patients proved that the risk of skin and subcutaneous tissue AEs was similar in both groups (RD $0.01,95 \% \mathrm{CI},-0.00$ to 0.02 , $P=0.28, \mathrm{I}^{2}=0 \%$ ) (Fig. S4).

\section{Ophthalmic AEs}

Out of the 30 studies [29, 30, 32, 34, 37, 40-45, 50, 51, 53, 54, $57,58,61,63-66,69,72-74,77,78]$ that reported ophthalmic AEs, two [61, 63] were performed in COVID-19 patients. A total of 37 ophthalmic AEs in the HCQ group and 22 in the control group were recorded. The meta-analysis demonstrated that increased risk of ophthalmic AEs in the HCQ group was not remarkable compared with the control group (RD 0.01, $95 \% \mathrm{CI},-0.00$ to $0.01, P=0.12, \mathrm{I}^{2}=0 \%$ ). A subgroup analysis based on diagnosis also found no positive results (Fig. S5).

\section{Cardiac AEs}

Nine [34, 38-40, 42, 45, 47, 61, 70] of the 53 studies reported the 12 cardiac AEs, with eight in the HCQ group and four in the control group. The findings of the meta-analysis indicated that the risks of cardiac AEs were comparable between the two groups (RD $0.00,95 \% \mathrm{CI},-0.01$ to $0.01, P=0.75, \mathrm{I}^{2}=$ 0\%) (Fig. S6).

\section{Treatment discontinuation due to AEs}

Twenty-nine studies $[27-36,39-41,43,44,46,47,49$, 50, 54, 56, 57, 59, 61, 63, 64, 66, 70, 78], including two studies $[61,63]$ in COVID-19 patients, declared treatment discontinuation due to AEs. The metaanalysis demonstrated that patients in the HCQ group had a higher risk of treatment discontinuation caused by AEs compared with the control group (RD 0.01, $95 \% \mathrm{CI}, 0.00$ to $0.03, P=0.02, \mathrm{I}^{2}=10 \%$ ) (Fig. S7). Nevertheless, it did not reach a statistical significance in the COVID-19 subgroup and the subgroup for other diseases. 
HCQ

Control

Risk Difference

Risk Difference

Studv or Subgroup Events Total Events Total Weight M-H, Random, 95\% Cl Year 1.1.1 COVID-19

Chen\# 2020

Tang 2020

Chen 2020

Boulware 2020

Subtotal $(95 \% \mathrm{Cl})$

Total events

$\begin{array}{rr}4 & 15 \\ 21 & 75 \\ 2 & 31 \\ 140 & 414 \\ & 535\end{array}$

$\begin{array}{rrr}3 & 15 & 0.6 \% \\ 7 & 75 & 2.4 \% \\ 0 & 31 & 2.9 \% \\ 59 & 407 & 4.2 \% \\ & 528 & 10.2 \%\end{array}$

167 69

Heterogeneity: $\mathrm{Tau}^{2}=0.00 ; \mathrm{Chi}^{2}=5.72, \mathrm{df}=3(\mathrm{P}=0.13) ; \mathrm{I}^{2}=48 \%$

Test for overall effect: $Z=3.78(P=0.0002)$

\subsubsection{Other diseases}

\begin{tabular}{|c|c|c|c|c|c|c|c|}
\hline Zeh 2020 & 48 & 52 & 43 & 46 & $2.9 \%$ & $-0.01[-0.11,0.09]$ & 2020 \\
\hline Horne 2020 & 24 & 32 & 20 & 30 & $1.0 \%$ & $0.08[-0.14,0.31]$ & 2020 \\
\hline Krawariti 2020 & 3 & 25 & 0 & 25 & $2.0 \%$ & $0.12[-0.02,0.26]$ & 2020 \\
\hline Liu 2019 & 7 & 30 & 2 & 30 & $1.5 \%$ & $0.17[-0.01,0.34]$ & 2019 \\
\hline Brazil 2018 & 34 & 36 & 15 & 18 & $1.4 \%$ & $0.11[-0.08,0.30]$ & 2018 \\
\hline Majzoobi 2018 & 11 & 89 & 17 & 88 & $2.8 \%$ & $-0.07[-0.18,0.04]$ & 2018 \\
\hline Kingsbury 2018 & 3 & 124 & 0 & 124 & $4.9 \%$ & $0.02[-0.01,0.06]$ & 2018 \\
\hline Lee 2018 & 24 & 98 & 21 & 98 & $2.5 \%$ & $0.03[-0.09,0.15]$ & 2018 \\
\hline Boonpiyathad 2017 & 5 & 28 & 3 & 27 & $1.4 \%$ & $0.07[-0.12,0.25]$ & 2017 \\
\hline Yokogawa 2017 & 57 & 77 & 19 & 26 & $1.3 \%$ & $0.01[-0.19,0.21]$ & 2017 \\
\hline Yoon 2017 & 3 & 15 & 0 & 11 & $1.0 \%$ & $0.20[-0.03,0.43]$ & 2017 \\
\hline Helal 2016 & 0 & 60 & 0 & 60 & $4.9 \%$ & $0.00[-0.03,0.03]$ & 2016 \\
\hline Pareek 2015 & 13 & 161 & 10 & 167 & $4.3 \%$ & $0.02[-0.03,0.08]$ & 2015 \\
\hline Meng 2014 & 3 & 36 & 2 & 36 & $2.5 \%$ & $0.03[-0.09,0.15]$ & 2014 \\
\hline Gottenberg 2014 & 2 & 56 & 3 & 64 & $3.8 \%$ & $-0.01[-0.08,0.06]$ & 2014 \\
\hline Jokar 2013 & 3 & 23 & 0 & 21 & $1.8 \%$ & $0.13[-0.02,0.28]$ & 2013 \\
\hline Das 2007 & 5 & 61 & 6 & 61 & $2.9 \%$ & $-0.02[-0.12,0.09]$ & 2007 \\
\hline Fong 2007 & 1 & 46 & 1 & 49 & $4.2 \%$ & $0.00[-0.06,0.06]$ & 2007 \\
\hline Sarzi-Puttini 2005 & 23 & 35 & 18 & 36 & $1.0 \%$ & $0.16[-0.07,0.38]$ & 2005 \\
\hline Gerstein 2002 & 3 & 69 & 1 & 66 & $4.2 \%$ & $0.03[-0.03,0.08]$ & 2002 \\
\hline Van Gool 2001 & 20 & 83 & 15 & 85 & $2.4 \%$ & $0.06[-0.06,0.19]$ & 2001 \\
\hline Van Jaarsveld 2000 & 59 & 120 & 23 & 67 & $2.0 \%$ & $0.15[0.00,0.29]$ & 2000 \\
\hline Charous 1998 & 0 & 8 & 0 & 9 & $1.3 \%$ & $0.00[-0.20,0.20]$ & 1998 \\
\hline Kavanaugh 1997 & 9 & 12 & 2 & 5 & $0.3 \%$ & $0.35[-0.14,0.84]$ & 1997 \\
\hline Sperber 1995 & 0 & 20 & 0 & 20 & $3.2 \%$ & $0.00[-0.09,0.09]$ & 1995 \\
\hline Esdaile 1995 & 25 & 59 & 19 & 60 & $1.6 \%$ & $0.11[-0.07,0.28]$ & 1995 \\
\hline Blackburn 1995 & 63 & 124 & 54 & 118 & $2.3 \%$ & $0.05[-0.08,0.18]$ & 1995 \\
\hline Williams 1994 & 2 & 40 & 0 & 31 & $3.4 \%$ & $0.05[-0.03,0.13]$ & 1994 \\
\hline Haar 1993 & 8 & 25 & 4 & 27 & $1.0 \%$ & $0.17[-0.05,0.40]$ & 1993 \\
\hline Clark 1993 & 28 & 65 & 28 & 65 & $1.6 \%$ & $0.00[-0.17,0.17]$ & 1993 \\
\hline Kruize 1993 & 1 & 10 & 0 & 9 & $0.9 \%$ & $0.10[-0.14,0.34]$ & 1993 \\
\hline Faawang 1993 & 8 & 31 & 12 & 29 & $1.0 \%$ & $-0.16[-0.39,0.08]$ & 1993 \\
\hline CHSG 1991 & 3 & 25 & 2 & 22 & $1.5 \%$ & $0.03[-0.15,0.20]$ & 1991 \\
\hline Quatraro 1990 & 3 & 22 & 0 & 16 & $1.6 \%$ & $0.14[-0.03,0.30]$ & 1990 \\
\hline Scott 1989 & 18 & 52 & 10 & 49 & $1.6 \%$ & $0.14[-0.03,0.31]$ & 1989 \\
\hline Bunch 1984 & 5 & 17 & 9 & 21 & $0.6 \%$ & $-0.13[-0.44,0.17]$ & 1984 \\
\hline Snook 1981 & 3 & 26 & 3 & 24 & $1.5 \%$ & $-0.01[-0.19,0.17]$ & 1981 \\
\hline Cooke 1977 & 0 & 25 & 0 & 25 & $3.7 \%$ & $0.00[-0.07,0.07]$ & 1977 \\
\hline Hansen 1976 & 1 & 75 & 0 & 78 & $4.8 \%$ & $0.01[-0.02,0.05]$ & 1976 \\
\hline Chrisman 1976 & 3 & 15 & 0 & 15 & $1.1 \%$ & $0.20[-0.02,0.42]$ & 1976 \\
\hline Subtotal $(95 \% \mathrm{Cl})$ & \multicolumn{2}{|r|}{2007} & \multirow{2}{*}{\multicolumn{2}{|c|}{1858}} & \multirow[t]{2}{*}{$89.8 \%$} & \multirow{2}{*}{\multicolumn{2}{|c|}{$0.03[0.01,0.04]$}} \\
\hline otal events & 531 & & & & & & \\
\hline
\end{tabular}

Heterogeneity: $\mathrm{Tau}^{2}=0.00 ; \mathrm{Chi}^{2}=45.72, \mathrm{df}=39(\mathrm{P}=0.21) ; \mathrm{I}^{2}=15 \%$

Test for overall effect: $Z=2.95(P=0.003)$

Total $(95 \% \mathrm{Cl})$

Total events

2542
$2386 \quad 100.0 \%$ 431
$0.07[-0.24,0.37] 2020$ $0.19[0.07,0.31] 2020$ $0.06[-0.04,0.17] 2020$ $0.19[0.14,0.25] 2020$ $0.15[0.07,0.23]$
M-H, Random, $95 \% \mathrm{Cl}$

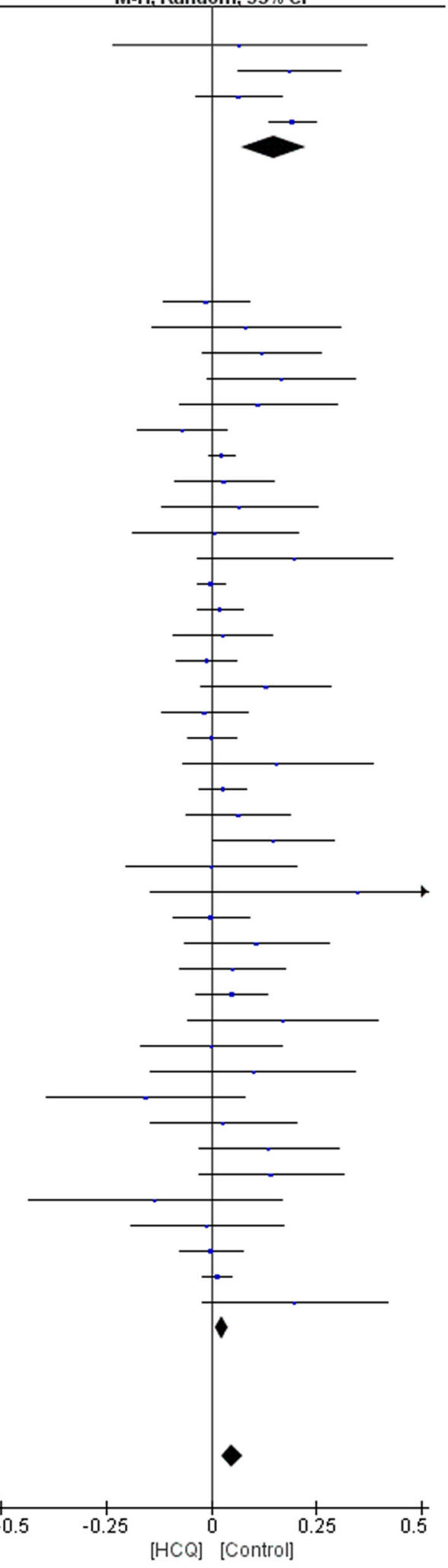

Test for overall effect: $Z=3.73(P=0.0002)$

Test for subaroun differences: $\mathrm{Chi}^{2}=9.37 . \mathrm{df}=1(\mathrm{P}=0.002) . \mathrm{I}^{2}=89.3 \%$

$0.05[0.02,0.07]$

Fig. 2 Forest plot of the risk of AEs between the HCQ group and control group. CI, confidence interval; M-H, Mantel-Haenszel; HCQ, hydroxychloroquine, CHSG, Canadian Hydroxychloroquine Study Group 


\section{SAEs}

Thirty-six $[28-34,36,38-40,42-46,48-50,53-55,57-63$, $67-71,73,76,78]$ of the 53 included studies, consisting of 4229 patients, reported SAEs. In the HCQ group, 2173 patients reported 55 SAEs, while in the control group, 2056 patients reported 38 SAEs. The cumulative number of SAEs in the HCQ group was not significantly greater than that in the control group (RD $0.00,95 \% \mathrm{CI},-0.00$ to $0.00, P=0.85, \mathrm{I}^{2}=$ 0\%) (Fig. S8).

\section{Sensitivity analysis}

Sensitivity analysis revealed that the meta-analysis results of all outcomes using the fixed-effects models were consistent with the random-effects models. The pooled estimated values using fixed-effects models were displayed in Table S5.

Moreover, we conducted sensitivity analyses by removing each included study one by one for all the outcomes, and no variation was found in the meta-analysis of all outcomes except for the ophthalmic AEs and treatment discontinuation due to AEs. After excluding the study of Pareek et al. [42], we noticed that the risk difference of ophthalmic AEs between the HCQ group and the control group was statistically significant (RD $0.01,95 \% \mathrm{CI}, 0.00$ to $0.02, P=0.04, \mathrm{I}^{2}=0 \%$ ). With respect to the treatment discontinuation due to AEs, when the publication of Boulware et al. [63] focusing on the postexposure prophylaxis for COVID-19 was eliminated, the increase in risk was close to statistical significance (RD $0.01,95 \% \mathrm{CI}$, -0.01 to $0.03, P=0.06, \mathrm{I}^{2}=14 \%$ ).

Concerning the gastrointestinal AEs and treatment discontinuation due to AEs, the meta-analysis of high-quality studies demonstrated that the HCQ group and the control group had similar risks. For other outcomes, the meta-analysis of highquality studies supported the primary analysis results. The meta-analysis of the high-quality studies using randomeffects models is listed in Table S6.

\section{Publication bias}

The funnel plots of all the outcomes had no obvious asymmetry, indicating that there was no significant publication bias of studies included in the outcomes (see Fig. S9).

\section{Discussion}

This systematic review enabled us to discover that the risk of total AEs in the HCQ group was significantly increased compared with that in the control group, and the risk difference was also found to be statistically significant in the COVID-19 subgroup and the subgroup for other diseases. Nonetheless, the results of the subgroup analysis based on the daily dose of
HCQ were not completely consistent with the overall results, possibly because the number and sample size of the studies in the high-dose group were limited and could not reach a statistical significance. The risks of gastrointestinal AEs, skin and subcutaneous tissue disorders AEs, and treatment discontinuation due to AEs in the HCQ group were higher than in the control group. It is worth mentioning that patients treated with HCQ did not have a significantly increased risk of ophthalmic AEs, cardiac AEs, and total SAEs compared to those who were not treated with HCQ.

Despite the fact that a series of studies and case reports [79-86] have found that HCQ could increase the risk of retinopathy, this review has demonstrated that the pooled incidence of ophthalmic AEs occurring in the HCQ group was not significantly increased compared with the control group and only two specified retinopathies $[51,62]$ were reported in the eligible studies. This observation might be accounted for by the fact that the follow-up periods of the randomized studies included in this review were not long enough. A retrospective study found that the potential risk factors for HCQ-induced were high doses and long-term ( $>5$ years) treatment by multivariate regression [87]. Nevertheless, most follow-up periods of the included studies in this review were within 12 months, and the longest one was about 40 months. The sensitivity analysis suggested that the difference in risk of ophthalmic AEs between the HCQ and control groups reached a statistical significance by removing the study of Pareek et al. [42].

In this review, the patients receiving HCQ suffered more from skin and subcutaneous tissues AEs than the patients in the control group. The commonly reported skin and subcutaneous tissues AEs were rashes, and other AEs such as pigmentation and itching were also frequently reported. There were two SAEs reported in the HCQ group, one being erythema multiforme and the other one being acute generalized erythematous pustulosis, while none were reported in the control group. Previous studies revealed that skin ADRs generally occurred 5 14 days after the beginning of HCQ therapy, and the rash was characterized as lichen-like, urticaria or simply rash. Additionally, the symptoms were generally mild, which could be relieved after withdrawal of therapy $[88,89]$. The skin and subcutaneous tissue SAEs associated with HCQ that were frequently reported in the literature were acute generalized exanthematous pustulosis (AGEP) [12-14, 90-93], pigmentation [15, 17, 94-100], Stevens-Johnson syndrome [19, $101]$, and toxic epidermal necrolysis $[18,102,103]$. One multinational case-control study suggested that HCQ or chloroquine was highly associated with AGEP [104]. Additionally, the risk factors identified in previous studies for HCQ-induced pigmentation were previous treatment with oral anticoagulants and/or antiplatelet agents as well as higher blood HCQ concentrations $[99,100]$.

A number of recent studies have declared the related cardiotoxicity of HCQ [8-11, 105-113], such as 
cardiomyopathy $[9-11,105,108,109,111,112]$ and arrhythmias [113]. In the present review, HCQ was similar to the placebo or non-intervention in the risk of cardiac AEs, and the cardiac SAEs of HCQ reported were arrhythmias and heart failure. A systematic review on chloroquine or HCQ induced cardiac toxicity indicated that the occurrence of cardiac AEs is rare, but generally more severe and may be irreversible [114]. The AEs associated with HCQ included cardiomyopathy, atrioventricular block, valve dysfunction, acute myocardial infarction, heart failure, and abnormal left ventricular ejection fraction. Among these cardiac AEs, the incidence of cardiomyopathy with HCQ was higher than with chloroquine [114]. Jankelson et al. found significant QT prolongations in patients with COVID-19 receiving HCQ by conducting a systemic review [113]. However, the evidence of QT prolongation by HCQ was mainly from observational studies with small sample size. Meanwhile, a retrospective multicenter cohort study of 1438 patients with laboratory-confirmed COVID-19 described that there were no significant differences between the groups receiving neither drug and each of the HCQ plus azithromycin and HCQ alone groups in logistic regression models [115].

As regards the most reported gastrointestinal AEs in the included studies, the results of the sensitivity analysis did not fully follow the results of the primary meta-analysis. We failed to find a source that could significantly reduce inter-study heterogeneity, and therefore this result should be treated with caution. The sensitivity analysis suggested that we should also pay attention to the robustness of the meta-analysis results regarding the treatment discontinuation due to AEs.

Concerning the four eligible studies [26, 60, 61, 63] on COVID-19, patients receiving HCQ had more total AEs than controls, which was similar to the overall results. The AEs recorded in other diseases might be referenced in the treatment of COVID-19 albeit the number and sample sizes of studies on COVID-19 were too small to obtain sufficient safety data, because the AE profile of HCQ might be expected to be similar in different populations and settings [23].

The COVID-19 patients enrolled in two studies [61, 63] were given a high daily dose of HCQ, leading to a remarkable rise in the occurrence of AEs. Notwithstanding, when the study was combined with high-dose studies on other diseases for a meta-analysis, the number of AEs did not increase significantly. The limited number and sample sizes of studies in the high-dose group made it difficult to determine whether a high daily dosage of HCQ would considerably increase the AEs. The findings of a study [116] conducted in systemic lupus erythematosus indicated that the AEs rates of patients receiving HCQ daily doses of $200 \mathrm{mg}, 400 \mathrm{mg}, 600 \mathrm{mg}$, and $800 \mathrm{mg}$ were $38.9 \%, 15.5 \%, 25 \%$, and $27.4 \%$, respectively, and no differences were identified between groups in terms of nausea, vomiting, diarrhea or blurred vision. Moreover, patients who received high HCQ doses for 7 months, including patients with a dose of $800 \mathrm{mg}$ once a day, had no significant AEs. Another dose-dependent study [117] enrolled 212 rheumatoid arthritis (RA) patients in a 6-week, double-blinded study comparing treatment with HCQ at $400 \mathrm{mg}, 800 \mathrm{mg}$, and $1200 \mathrm{mg}$ daily, and the results revealed that gastrointestinal AEs induced by HCQ were dose-related, while ocular AEs were dose-independent.

Withal, there are several limitations to this study. First, the definition and determination of AEs in the included studies were not completely consistent, and we could only rely on the published data for systematic review. As non-primary outcomes in the original studies, some studies merely reported the total AEs or SAEs without stating every specific AE, leading to the inaccuracy of certain reported AEs. Second, we basically enrolled RCTs representing the exclusion of patients at high risk of harm [118], there was a lack of enough time to determine long-term harmful effects, and the small sample size made it difficult to detect rare unusual events [119]. Third, most participants enrolled in this review's eligible studies were non-COVID-19 patients, the sample size of COVID19 studies were too small to provide enough information on the safety of HCQ in COVID-19 patients. Although the AEs profiles in other diseases might provide some sort of indirect evidence, attempting to apply the data from non-COVID-19 participants to the current pandemic is limited by the differences in treatment.

\section{Conclusion}

HCQ is associated with more total AEs, gastrointestinal AEs, and skin and subcutaneous tissue AEs compared with placebo or no intervention in the overall population. Considering the small number of COVID-19 participants included, we should be wary regarding the results stipulating that HCQ increases the incidence of AEs in patients with COVID-19, and strive to confirm these results in the future through well-designed studies with larger sample sizes. Even though the current evidence is not strong enough, clinical practitioners and patients should be alert to the AEs of HCQ during the treatment of COVID19.

Contributors All authors contributed to the study conception and design. Qianzhou Lv and Xiaoyu Li proposed the study protocol and supervised the progress of the work. Can Chen and Kunming Pan worked on the literature search and study selection, data extraction, assessment of risk of bias, data synthesis, and manuscript writing. Bingjie Wu and Zhangzhang Chen assisted in solving various professional problems encountered during the work and interpreting the results. Xiaoye $\mathrm{Li}$ and Qing Xu doublechecked the manuscript. All authors read and approved the final manuscript.

Funding This study was funded by Key Clinical Specialty of Shanghai (Clinical Pharmacy) (No.shslczdzk06504). 


\section{Compliance with ethical standards}

Competing interests The authors declare that they have no conflict of interest.

Ethics approval Not applicable.

\section{References}

1. Wang M, Cao R, Zhang L, Yang X, Liu J, Xu M et al (2020) Remdesivir and chloroquine effectively inhibit the recently emerged novel coronavirus (2019-nCoV) in vitro. Cell Res 30(3):269-271. https://doi.org/10.1038/s41422-020-0282-0

2. General Office of the Health Commission (2020) Covid-19 prevention and control plan (6th edn). http://www.nhc.gov.cn/jkj/ s3577/202003/4856d5b0458141fa9f376853224d41d7/files/ 4132bf035bc242478a6eaf157eb0d979.pdf. Accessed 19 Mar 2020

3. General Office of the Health Commission (2020) Covid-19 prevention and control plan (trial 7th edn). 2020. http://www.nhc.gov.cn/ yzygj/s7653p/202003/46c9294a7dfe4cef80dc7f5912eb1989/files/ ce3e6945832a438eaae415350a8ce964.pdf. Accessed 19 Mar 2020

4. Pareek A, Khopkar U, Sacchidanand S, Chandurkar N, Naik GS (2008) Comparative study of efficacy and safety of hydroxychloroquine and chloroquine in polymorphic light eruption: a randomized, double-blind, multicentric study. Indian J Dermatol Venereol Leprol 74(1):18-22. https://doi.org/10.4103/0378-6323. 38401

5. Finbloom DS, Silver K, Newsome DA, Gunkel R (1985) Comparison of hydroxychloroquine and chloroquine use and the development of retinal toxicity. J Rheumatol 12(4):692-694

6. Srinivasa A, Tosounidou S, Gordon C (2017) Increased incidence of gastrointestinal side effects in patients taking hydroxychloroquine: a brand-related issue? J Rheumatol 44(3): 398. https://doi.org/10.3899/jrheum.161063

7. Al-Bari MA (2015) Chloroquine analogues in drug discovery: new directions of uses, mechanisms of actions and toxic manifestations from malaria to multifarious diseases. J Antimicrob Chemother 70(6):1608-1621. https://doi.org/10.1093/jac/dkv018

8. Ghincea A, Allsop J, Groves DW, Rizeq M, Revelo MP, Raghavan S (2019) A failing heart: a new diagnosis of heart failure due to hydroxychloroquine-induced cardiomyopathy. J Gen Intern Med 34(2):S440. https://doi.org/10.1007/11606.1525-1497

9. Abbi B, Patel SN, Blanco I, Kumthekar A, Schwartz D (2019) A growing concern: cardiomyopathy with long term hydroxychloroquine use. J Investig Med 67(4):807. https://doi. org/10.1136/jim-2019-001036.46

10. Yogasundaram H, Hung W, Paterson ID, Sergi C, Oudit GY (2018) Chloroquine-induced cardiomyopathy: a reversible cause of heart failure. ESC heart failure 5(3):372-375. https://doi.org/ 10.1002/ehf 2.12276

11. Dogar MU, Shah NN, Ishtiaq S, Shah PN, Shah P, Mathew S et al (2018) Hydroxychloroquine-induced restrictive cardiomyopathy: a case report. Postgrad Med J 94(1109):185-186. https://doi.org/ 10.1136/postgradmedj-2017-135236

12. Liccioli G, Marrani E, Giani T, Simonini G, Barni S, Mori F (2019) The first pediatric case of acute generalized Exanthematous Pustulosis caused by hydroxychloroquine. Pharmacology 104(1-2):57-59. https://doi.org/10.1159/ 000500406

13. Duman H, Topal IO, Kocaturk E, Cure K, Mansuroglu I (2017) Acute generalized exanthematous pustulosis induced by hydroxychloroquine: a case with atypical clinical presentation.
An Bras Dermatol 92(3):404-406. https://doi.org/10.1590/ abd1806-4841.20175561

14. Charfi O, Kastalli S, Sahnoun R, Lakhoua G (2015) Hydroxychloroquine-induced acute generalized exanthematous pustulosis with positive patch-testing. Indian journal of pharmacology 47(6):693-694. https://doi.org/10.4103/0253-7613.169589

15. Ivo R, Lopes CA, Reis R (2018) Woman in grey: hydroxychloroquine-induced hyperpigmentation. BMJ Case Rep 11(1):e227305. https://doi.org/10.1136/bcr-2018-227305

16. Kasper RS, Flueckiger B, Gobbi S, Lautenschlager S, Borelli S (2014) Hydroxychloroquine-induced hyperpigmentation. JDDG 12(2):158-161. https://doi.org/10.1111/ddg.12232

17. Mir A, Boyd KP, Meehan SA, McLellan B (2013) Hydroxychloroquine-induced hyperpigmentation. Dermatol Online J 19(12):19

18. Lateef A, Tan KB, Lau TC (2009) Acute generalized exanthematous pustulosis and toxic epidermal necrolysis induced by hydroxychloroquine. Clin Rheumatol 28(12):1449-1452. https:// doi.org/10.1007/s10067-009-1262-4

19. Callaly EL, FitzGerald O, Rogers S (2008) Hydroxychloroquineassociated, photo-induced toxic epidermal necrolysis. Clin Exp Dermatol 33(5):572-574. https://doi.org/10.1111/j.1365-2230. 2008.02704.x

20. Liberati A, Altman DG, Tetzlaff J, Mulrow C, Gotzsche PC, Ioannidis JP et al (2009) The PRISMA statement for reporting systematic reviews and meta-analyses of studies that evaluate healthcare interventions: explanation and elaboration. BMJ 339: b2700. https://doi.org/10.1136/bmj.b2700

21. What is a Serious Adverse Event? 2016. https://www.fda.gov/ safety/reporting-serious-problems-fda/what-serious-adverseevent. Accessed 19 Mar 2020

22. Brown EG, Wood L, Wood S (1999) The medical dictionary for regulatory activities (MedDRA). Drug Saf 20(2):109-117. https:// doi.org/10.2165/00002018-199920020-00002

23. Higgins JPT TJ, Chandler J, Cumpston M, Li T, Page MJ, Welch VA (editors) (2019) Cochrane Handbook for Systematic Reviews of Interventions version 6.0 (updated July 2019). Available from www.training.cochrane.org/handbook

24. Higgins JP, Altman DG, Gotzsche PC, Juni P, Moher D, Oxman $\mathrm{AD}$ et al (2011) The Cochrane Collaboration's tool for assessing risk of bias in randomised trials. BMJ (Clinical research ed) 343: d5928. https://doi.org/10.1136/bmj.d5928

25. The Cochrane Collaboration (2014) Review Manager (RevMan). [Computer Program]. Version 5.3. Copenhagen DTNCC

26. Chen J, Liu DP, Liu L, Liu P et al (2020) A pilot study of hydroxychloroquine in treatment of patients with common coronavirus disease-19 (COVID-19). J Zhejiang Univ (Med Sci):1-8

27. Blackburn WD Jr, Prupas HM, Silverfield JC, Poiley JE, Caldwell JR, Collins RL et al (1995) Tenidap in rheumatoid arthritis. A 24week double-blind comparison with hydroxychloroquine-pluspiroxicam, and piroxicam alone. Arthritis Rheum 38(10):14471456. https://doi.org/10.1002/art.1780381011

28. Boonpiyathad T, Sangasapaviliya A (2017) Hydroxychloroquine in the treatment of anti-histamine refractory chronic spontaneous urticaria, randomized single-blinded placebo-controlled trial and an open label comparison study. Eur Ann Allergy Clin Immunol 49(5):220 224. https://doi.org/10.23822/EurAnnACI.1764-1489.11

29. Clark P, Casas E, Tugwell P, Medina C, Gheno C, Tenorio G et al (1993) Hydroxychloroquine compared with placebo in rheumatoid arthritis. A randomized controlled trial. Ann Intern Med 119(11):1067-1071. https://doi.org/10.7326/0003-4819-119-11199312010-00002

30. Esdaile JM, Suissa S, Shiroky JB, Lamping D, Tsakonas E, Anderson D et al (1995) A randomized trial of hydroxychloroquine in early rheumatoid arthritis: the HERA study. Am J Med 98(2):156-168. https://doi.org/10.1016/S0002-9343(99)80399-4 
31. Gottenberg JE, Ravaud P, Puéchal X, Le Guern V, Sibilia J, Goeb $\mathrm{V}$ et al (2014) Effects of hydroxychloroquine on symptomatic improvement in primary Sjögren syndrome: the JOQUER randomized clinical trial. Jama 312(3):249-258. https://doi.org/10. 1001/jama.2014.7682

32. Haar D, Sølvkjaer M, Unger B, Rasmussen KJ, Christensen L, Hansen TM (1993) A double-blind comparative study of hydroxychloroquine and dapsone, alone and in combination, in rheumatoid arthritis. Scand J Rheumatol 22(3):113-118. https:// doi.org/10.3109/03009749309099254

33. Hansen EH, Jessing P, Lindewald H (1976) Hydroxychloroquine sulphate in prevention of deep venous thrombosis following fracture of the hip, pelvis, or thoracolumbar spine. J Bone Joint Surg Am 58(8):1089-1093. https://doi.org/10.2106/00004623197658080-00008

34. Horne GA, Stobo J, Kelly C, Mukhopadhyay A, Latif AL, DixonHughes J et al (2020) A randomised phase II trial of hydroxychloroquine and imatinib versus imatinib alone for patients with chronic myeloid leukaemia in major cytogenetic response with residual disease. Leukemia. https://doi.org/10.1038/ s41375-019-0700-9

35. Jokar M, Mirfeizi Z, Keyvanpajouh K (2013) The effect of hydroxychloroquine on symptoms of knee osteoarthritis: a double-blind randomized controlled clinical trial. Iran J Med Sci 38(3):221-226

36. Karasic TB, O'Hara MH, Loaiza-Bonilla A, Reiss KA, Teitelbaum UR, Borazanci E et al (2019) Effect of gemcitabine and nab-paclitaxel with or without hydroxychloroquine on patients with advanced pancreatic cancer: a phase 2 randomized clinical trial. JAMA oncology 5(7):993-998. https://doi.org/10.1001/jamaoncol.2019.0684

37. Kavanaugh A, Adams-Huet B, Jain R, Denke M, McFarlin J (1997) Hydroxychloroquine effects on lipoprotein profiles (the HELP trial): a double-blind, randomized, placebo-controlled, pilot study in patients with systemic lupus erythematosus. J Clin Rheumatol 3(1):3-8. https://doi.org/10.1097/00124743199702000-00002

38. Kingsbury SR, Tharmanathan P, Keding A, Ronaldson SJ, Grainger A, Wakefield RJ et al (2018) Hydroxychloroquine effectiveness in reducing symptoms of hand osteoarthritis a randomized trial. Ann Intern Med 168(6):385-395. https://doi.org/10. 7326/M17-1430

39. Lee W, Ruijgrok L, Boxma-de Klerk B, Kok MR, Kloppenburg M, Gerards A et al (2018) Efficacy of hydroxychloroquine in hand osteoarthritis: a randomized, double-blind, placebo-controlled trial. Arthritis Care Res 70(9):1320-1325. https://doi.org/10.1002/acr. 23471

40. Liu LJ, Yang YZ, Shi SF, Bao YF, Yang C, Zhu SN et al (2019) Effects of hydroxychloroquine on proteinuria in IgA nephropathy: a randomized controlled trial. Am J Kidney Dis 74(1):15-22. https://doi.org/10.1053/j.ajkd.2019.01.026

41. Majzoobi MM, Hashemi SH, Mamani M, Keramat F, Poorolajal J, Ghasemi Basir HR (2018) Effect of hydroxychloroquine on treatment and recurrence of acute brucellosis: a single-blind, randomized clinical trial. Int J Antimicrob Agents 51(3):365-369. https:// doi.org/10.1016/j.ijantimicag.2017.08.009

42. Pareek A, Chandurkar N, Thulaseedharan NK, Legha R, Agarwal M, Mathur SL et al (2015) Efficacy and safety of fixed dose combination of atorvastatin and hydroxychloroquine: a randomized, double-blind comparison with atorvastatin alone among Indian patients with dyslipidemia. Curr Med Res Opin 31(11): 2105-2117. https://doi.org/10.1185/03007995.2015.1087989

43. Paton NI, Goodall RL, Dunn DT, Franzen S, Collaco-Moraes Y, Gazzard BG et al (2012) Effects of hydroxychloroquine on immune activation and disease progression among HIV-infected patients not receiving antiretroviral therapy: a randomized controlled trial. JAMA 308(4):353-361. https://doi.org/10.1001/jama.2012. 6936

44. Scott DL, Dawes PT, Tunn E, Fowler PD, Shadforth MF, Fisher J et al (1989) Combination therapy with gold and hydroxychloroquine in rheumatoid arthritis: a prospective, randomized, placebo-controlled study. Br J Rheumatol 28(2):128133. https://doi.org/10.1093/rheumatology/28.2.128

45. Sperber K, Louie M, Kraus T, Proner J, Sapira E, Lin S et al (1995) Hydroxychloroquine treatment of patients with human immunodeficiency virus type 1. Clin Ther 17(4):622-636. https:// doi.org/10.1016/0149-2918(95)80039-5

46. Yokogawa N, Eto H, Tanikawa A, Ikeda T, Yamamoto K, Takahashi $\mathrm{T}$ et al (2017) Effects of hydroxychloroquine in patients with cutaneous lupus erythematosus: a multicenter, double-blind, randomized, parallel-group trial. Arthritis Rheumatol 69(4):791-799. https://doi.org/10.1002/art.40018

47. Zeh H, Bahary N, Boone BA, Singhi AD, Miller-Ocuin JL, Normolle DP et al (2020) A randomized phase II preoperative study of autophagy inhibition with high-dose hydroxychloroquine and gemcitabine/nab-paclitaxel in pancreatic Cancer patients. Clin Cancer Res. https://doi.org/10.1158/1078-0432.Ccr-19-4042

48. Erkan D, Unlu O, Sciascia S, Belmont HM, Branch DW, Cuadrado MJ et al (2018) Hydroxychloroquine in the primary thrombosis prophylaxis of antiphospholipid antibody positive patients without systemic autoimmune disease. Lupus 27(3):399 406. https://doi.org/10.1177/0961203317724219

49. Helal GK, Gad MA, Abd-Ellah MF, Eid MS (2016) Hydroxychloroquine augments early virological response to pegylated interferon plus ribavirin in genotype- 4 chronic hepatitis C patients. J Med Virol 88(12):2170-2178. https://doi.org/10.1002/ jmv. 24575

50. Das SK, Pareek A, Mathur DS, Wanchu A, Srivastava R, Agarwal GG et al (2007) Efficacy and safety of hydroxychloroquine sulphate in rheumatoid arthritis: a randomized, double-blind, placebo controlled clinical trial-an Indian experience. Curr Med Res Opin 23(9):2227-2234. https://doi.org/10.1185/030079907x219634

51. Gerstein HC, Thorpe KE, Wayne Taylor D, Brian Haynes R (2002) The effectiveness of hydroxychloroquine in patients with type 2 diabetes mellitus who are refractory to sulfonylureas-a randomized trial. Diabetes Res Clin Pract 55(3):209-219. https://doi. org/10.1016/S0168-8227(01)00325-4

52. Desta M, Tadesse A, Gebre N, Barci BM, Torrey EF, Knable MB (2002) Controlled trial of hydroxychloroquine in schizophrenia. J Clin Psychopharmacol 22(5):507-510. https://doi.org/10.1097/ 00004714-200210000-00011

53. Van Gool WA, Weinstein HC, Scheltens PK, Walstra GJM (2001) Effect of hydroxychloroquine on progression of dementia in early Alzheimer's disease: an 18-month randomised, double-blind, placebo-controlled study. Lancet 358(9280):455-460. https://doi. org/10.1016/S0140-6736(01)05623-9

54. Van Jaarsveld CHM, Jahangier ZN, Jacobs JWG, Blaauw AAM, Van Albada-Kuipers GA, Ter Borg EJ et al (2000) Toxicity of anti-rheumatic drugs in a randomized clinical trial of early rheumatoid arthritis. Rheumatology 39(12):1374-1382. https://doi. org/10.1093/rheumatology/39.12.1374

55. Charous BL, Halpern EF, Steven GC (1998) Hydroxychloroquine improves airflow and lowers circulating IgE levels in subjects with moderate symptomatic asthma. J Allergy Clin Immunol 102(2): 198-203. https://doi.org/10.1016/s0091-6749(98)70086-7

56. Williams HJ, Egger MJ, Singer JZ, Willkens RF, Kalunian KC, Clegg DO et al (1994) Comparison of hydroxychloroquine and placebo in the treatment of the arthropathy of mild systemic lupus erythematosus. J Rheumatol 21(8):1457-1462

57. Faarvang KL, Egsmose C, Kryger P, Pødenphant J, IngemanNielsen M, Hansen TM (1993) Hydroxychloroquine and sulphasalazine alone and in combination in rheumatoid arthritis: 
a randomised double blind trial. Ann Rheum Dis 52(10):711-715. https://doi.org/10.1136/ard.52.10.711

58. Quatraro A, Consoli G, Magno M, Caretta F, Nardozza A, Ceriello A et al (1990) Hydroxychloroquine in decompensated, treatment-refractory noninsulin-dependent diabetes mellitus. A new job for an old drug? Ann Intern Med 112(9):678-681. https://doi.org/10.7326/0003-4819-112-9-678

59. Bunch TW, O'Duffy JD, Tompkins RB, O'Fallon WM (1984) Controlled trial of hydroxychloroquine and D-penicillamine singly and in combination in the treatment of rheumatoid arthritis. Arthritis Rheum 27(3):267-276. https://doi.org/10.1002/art. 1780270304

60. Chen Z, Hu J, Zhang Z, Jiang S, Han S, Yan D et al (2020) Efficacy of hydroxychloroquine in patients with COVID-19: results of a randomized clinical trial. medRxiv:2020.03.22.20040758. https://doi. org/10.1101/2020.03.22.20040758

61. Tang W, Cao Z, Han M, Wang Z, Chen J, Sun W et al (2020) Hydroxychloroquine in patients with COVID-19: an open-label, randomized, controlled trial. BMJ 369:m1849. https://doi.org/10. 1136/bmj.m1849

62. Kravvariti E, Koutsogianni A, Samoli E, Sfikakis PP, Tektonidou MG (2020) The effect of hydroxychloroquine on thrombosis prevention and antiphospholipid antibody levels in primary antiphospholipid syndrome: a pilot open label randomized prospective study. Autoimmun Rev 19(4):102491. https://doi.org/ 10.1016/j.autrev.2020.102491

63. Boulware DR, Pullen MF, Bangdiwala AS, Pastick KA, Lofgren SM, Okafor EC et al (2020) A randomized trial of hydroxychloroquine as Postexposure prophylaxis for Covid-19. N Engl J Med. https://doi.org/10.1056/NEJMoa2016638

64. Brazil L, Swampillai A, Mak K, Hackshaw A, Edwards D, Mesiri P et al (2018) Hydroxychloroquine and short course radiotherapy for elderly patients with glioma: a randomised study. NeuroOncology 20:iii246. https://doi.org/10.1093/neuonc/noy139

65. Yoon CH, Lee HJ, Lee EY, Lee EB, Lee WW, Kim MK et al (2016) Effect of hydroxychloroquine treatment on dry eyes in subjects with primary Sjögren's syndrome: a double-blind randomized control study. J Korean Med Sci 31(7):1127-1135. https://doi.org/10.3346/jkms.2016.31.7.1127

66. Meng J, Lu Y, Dong X, Liu H (2014) Long-term effects of hydroxychloroquine on metabolism of serum lipids and left ventricular structure and function in patients of systemic lupus erythematosus. Zhonghua Yi Xue Za Zhi 94(13):965-968

67. Abou-Raya S, Abou-Raya A, Khadrawe T (2014) Efficacy of hydroxychloroquine in the treatment of symptomatic knee osteoarthritis in older adults: a randomized placebo-controlled trial. Ann Rheum Dis 73. https://doi.org/10.1136/annrheumdis-2014-eular.2764

68. Chen F, Xue B, Wang H (2012) Analysis of the clinical efficacy of yiqi fumai injection combined hydroxychloroquine sulfate tablet for treating Sjogren's syndrome. Zhongguo Zhong Xi Yi Jie He Za Zhi 32(12):1621-1623

69. Fong T, Trinkaus K, Adkins D, Vij R, Devine SM, Tomasson M et al (2007) A randomized double-blind trial of hydroxychloroquine for the prevention of chronic graft-versushost disease after allogeneic peripheral blood stem cell transplantation. Biol Blood Marrow Transplant 13(10):1201-1206. https:// doi.org/10.1016/j.bbmt.2007.06.012

70. Sarzi-Puttini P, D'Ingianna E, Fumagalli M, Scarpellini M, Fiorini $\mathrm{T}$, Chérié-Lignière EL et al (2005) An open, randomized comparison study of cyclosporine $\mathrm{A}$, cyclosporine $\mathrm{A}+$ methotrexate and cyclosporine $\mathrm{A}+$ hydroxychloroquine in the treatment of early severe rheumatoid arthritis. Rheumatol Int 25(1):15-22. https:// doi.org/10.1007/s00296-003-0384-2

71. Reeves GE, Boyle MJ, Bonfield J, Dobson P, Loewenthal M (2004) Impact of hydroxychloroquine therapy on chronic urticaria: chronic autoimmune urticaria study and evaluation. Intern Med J 34(4):182186. https://doi.org/10.1111/j.1444-0903.2004.00532.x

72. Levy RA, Vilela VS, Cataldo MJ, Ramos RC, Duarte JL, Tura BR et al (2001) Hydroxychloroquine (HCQ) in lupus pregnancy: double-blind and placebo-controlled study. Lupus 10(6):401404. https://doi.org/10.1191/096120301678646137

73. Kruize AA, Hené RJ, Kallenberg CG, van Bijsterveld OP, van der Heide A, Kater L et al (1993) Hydroxychloroquine treatment for primary Sjögren's syndrome: a two year double blind crossover trial. Ann Rheum Dis 52(5):360-364. https://doi.org/10.1136/ard.52.5.360

74. Murphy GM, Hawk JL, Magnus IA (1987) Hydroxychloroquine in polymorphic light eruption: a controlled trial with drug and visual sensitivity monitoring. Br J Dermatol 116(3):379-386. https://doi.org/10.1111/j.1365-2133.1987.tb05852.x

75. Snook GA, Chrisman OD, Wilson TC (1981) Thromboembolism after surgical treatment of hip fractures. Clin Orthop Relat Res 155:21-24

76. Cooke ED, Dawson MH, Ibbotson RM, Bowcock SA, Ainsworth ME, Pilcher MF (1977) Failure of orally administered hydroxychloroquine sulphate to prevent venous thromboembolism following elective hip operations. J Bone Joint Surg Am 59(4):496-500

77. Chrisman OD, Snook GA, Wilson TC, Short JY (1976) Prevention of venous thromboembolism by administration of hydroxychloroquine. A preliminary report. J Bone Joint Surg Am 58(7):918-920

78. Canadian Hydroxychloroquine Study Group (1991) A randomized study of the effect of withdrawing hydroxychloroquine sulfate in systemic lupus erythematosus. N Engl J Med 324(3):150 154. https://doi.org/10.1056/nejm199101173240303

79. Kowalski T, Baker C, Mack HG (2018) Hydroxychloroquine retinal toxicity in two patients with dermatological conditions. Australas $\mathrm{J}$ Dermatol 59(4):e266-e2e8. https://doi.org/10.1111/ajd.12827

80. Allard AB, Bristow E, Coombes G, Hickey S, Johnson H, Mootoo $\mathrm{R}$ et al (2017) Hydroxychloroquine-induced retinal toxicity. Rheumatology 56:ii61-iii2. https://doi.org/10.1093/ rheumatology/kex062

81. Navajas EV, Krema H, Hammoudi DS, Lipton JH, Simpson ER, Boyd S et al (2015) Retinal toxicity of high-dose hydroxychloroquine in patients with chronic graft-versus-host disease. Can J Ophthalmol 50(6):442-450. https://doi.org/10.1016/j. jcjo.2015.08.003

82. Michaelides M, Stover NB, Francis PJ, Weleber RG (2011) Retinal toxicity associated with hydroxychloroquine and chloroquine: risk factors, screening, and progression despite cessation of therapy. Arch Ophthalmol 129(1):30-39. https://doi.org/10.1001/ archophthalmol.2010.321

83. Klinger G, Morad Y, Westall CA, Laskin C, Spitzer KA, Koren G et al (2001) Ocular toxicity and antenatal exposure to chloroquine or hydroxychloroquine for rheumatic diseases. Lancet 358(9284): 813-814. https://doi.org/10.1016/s0140-6736(01)06004-4

84. Proano C, Kimball GP (2019) Hydroxychloroquine retinal toxicity. N Engl J Med 380(17):e27. https://doi.org/10.1056/ NEJMicm 1304542

85. Piggott KD, Apte R (2018) Hydroxychloroquine-induced retinal toxicity in systemic lupus erythematosus. Indian J Ophthalmol 66(12):1861-1862. https://doi.org/10.4103/ijo.IJO_899_18

86. Parikh VS, Modi YS, Au A, Ehlers JP, Srivastava SK, Schachat AP et al (2016) Nonleaking cystoid macular edema as a presentation of hydroxychloroquine retinal toxicity. Ophthalmology 123(3):664-666. https://doi.org/10.1016/j.ophtha.2015.09.011

87. Jorge A, Ung C, Young LH, Melles RB, Choi HK (2018) Hydroxychloroquine retinopathy - implications of research advances for rheumatology care. Nat Rev Rheumatol 14(12):693703. https://doi.org/10.1038/s41584-018-0111-8 
88. Gonzalez CD, Hansen C, Clarke JT (2019) Adverse cutaneous drug reactions with antimalarials in cutaneous lupus and dermatomyositis: a retrospective cohort study. J Am Acad Dermatol 81(3): 859-860. https://doi.org/10.1016/j.jaad.2019.04.068

89. Kishi C, Motegi SI, Yasuda M, Ishikawa O (2018) Therapeutic efficacy and adverse events of hydroxychloroquine administration in Japanese systemic/cutaneous lupus erythematosus patients. J Dermatol 45(8):1020-1022. https://doi.org/10.1111/1346-8138. 14512

90. Pastushenko I, Gracia-Cazaña T, Morales-Moya AL, Grasa MP (2014) Acute cutaneous pustular eruption due to hydroxychloroquine. Medicina Clinica 143(7):e13. https://doi.org/10.1016/j.medcli.2014. 04.003

91. Wiles ME, Klein R, Dressler DD, Rollin F (2013) Acute generalized exanthematous pustulosis in a lupus patient recently initiating hydroxychloroquine. J Gen Intern Med 28:S278

92. Paradisi A, Bugatti L, Sisto T, Filosa G, Amerio PL, Capizzi R (2008) Acute generalized exanthematous pustulosis induced by hydroxychloroquine: three cases and a review of the literature. Clin Ther 30(5):930-940. https://doi.org/10.1016/j.clinthera. 2008.05.014

93. Martins A, Lopes LC, Paiva Lopes MJ, Rodrigues JC (2006) Acute generalized exanthematous pustulosis induced by hydroxychloroquine. Eur J Dermatol 16(3):317-318

94. Ladan M, Shahid C (2019) A pigmented palatehydroxychloroquine-related oral hyperpigmentation. J Oral Pathol Med 48:50. https://doi.org/10.1111/jop.12796

95. Sifuentes Giraldo WA, Grandal Platero M, de la Puente Bujidos C, Gámir Gámir ML (2013) Generalized skin hyperpigmentation and longitudinal melanonychia secondary to treatment with hydroxychloroquine in systemic lupus erythematosus. Reumatologia Clinica 9(6):381-382. https://doi.org/10.1016/j. reuma.2012.12.004

96. Kalampalikis A, Goetze S, Elsner P (2012) Isolated hyperpigmentation of the oral mucosa due to hydroxychloroquine. J Dtsch Dermatol Ges 10(12):921-922. https://doi.org/10.1111/j.16100387.2012.08055.x

97. Morrison LK, Nordlund JJ, Heffernan MP (2009) Persistent cutaneous hyperpigmentation due to hydroxychloroquinone one year after therapy discontinuation. Dermatol Online J. 15(12):15

98. Melikoglu MA, Melikoglu M, Gurbuz U, Budak BS, Kacar C (2008) Hydroxychloroquine-induced hyperpigmentation: a case report. J Clin Pharm Ther 33(6):699-701. https://doi.org/10. 1111/j.1365-2710.2008.00955.x

99. Bahloul E, Jallouli M, Garbaa S, Marzouk S, Masmoudi A, Turki $\mathrm{H}$ et al (2017) Hydroxychloroquine-induced hyperpigmentation in systemic diseases: prevalence, clinical features and risk factors: a cross-sectional study of 41 cases. Lupus. 26(12):1304-1308. https://doi.org/10.1177/0961203317700486

100. Jallouli M, Frances C, Piette JC, DLT H, Moguelet P, Factor C et al (2013) Hydroxychloroquine-induced pigmentation in patients with systemic lupus erythematosus: a case-control study. JAMA Dermatol 149(8):935-940. https://doi.org/10.1001/jamadermatol. 2013.709

101. Leckie MJ, Rees RG (2002) Stevens-Johnson syndrome in association with hydroxychloroquine treatment for rheumatoid arthritis. Rheumatology 41(4):473-474. https://doi.org/10.1093/ rheumatology/41.4.473

102. Jindal L, Welgemoed S, Smith R, Dunn S, Subiramanian S, Gowdie P et al (2017) A rare case of chronic non granulomatous supraglottitis and toxic epidermal necrolysis (ten) secondary to its treatment in a teenage girl. Intern Med J 47:10. https://doi.org/10. 1111/imj.18_13578

103. Cameron MC, Word AP, Dominguez A (2014) Hydroxychloroquine-induced fatal toxic epidermal necrolysis complicated by angioinvasive rhizopus. Dermatology Online J 20(11)

104. Sidoroff A, Dunant A, Viboud C, Halevy S, Bavinck JN, Naldi L et al (2007) Risk factors for acute generalized exanthematous pustulosis (AGEP)-results of a multinational case-control study (EuroSCAR). Br J Dermatol 157(5):989-996. https://doi.org/10. 1111/j.1365-2133.2007.08156.x

105. Vinnakota S, van Zyl M, Geske J (2019) Hydroxychloroquine cardiomyopathy in a patient with gene positive hypertrophic cardiomyopathy. J Am Coll Cardiol 73(9 Supplement 1):2148. https://doi.org/10.1016/S0735-1097(19)32754-8

106. Grzeskowiak M, Pu D (2019) Hydroxychloroquine toxicity leading to cardiac arrest in a 23-year-old. J Gen Intern Med 34(2): S551-S5S2. https://doi.org/10.1007/11606.1525-1497

107. Chang ICY, Bois JP, Bois MC, Maleszewski JJ, Johnson GB, Grogan M (2018) Hydroxychloroquine-mediated cardiotoxicity with a false-positive $(99 \mathrm{~m})$ technetium-labeled pyrophosphate scan for transthyretin-related cardiac amyloidosis. Circ Cardiovasc Imaging 11(1):e007059. https://doi.org/10.1161/ circimaging.117.007059

108. Shaikh S, Grewal V, Turk A, Montfort JH, Slawsky M, Catanzaro JC (2017) A rare cause of myocardial injury in a patient with systemic lupus erythematosus: hydroxychloroquine induced cardiomyopathy. J Am Coll Cardiol 69(11):2376. https://doi.org/10. 1016/S0735-1097(17)35765-0

109. Sabato LA, Mendes LA, Cox ZL (2017) Restrictive cardiomyopathy associated with long-term use of hydroxychloroquine for systemic lupus erythematosus. J Pharm Pract 30(5):571-575. https:// doi.org/10.1177/0897190016655726

110. Shaikh M, Chitale A, Stratton R (2015) Hydroxychloroquine induced cardiotoxicity: a rare complication of a common drug. Rheumatology 54:i56-ii7. https://doi.org/10.1093/rheumatology/ kev088.020

111. Yogasundaram H, Putko BN, Tien J, Paterson DI, Cujec B, Ringrose J et al (2014) Hydroxychloroquine-induced cardiomyopathy: case report, pathophysiology, diagnosis, and treatment. Can J Cardiol 30(12):1706-1715. https://doi.org/10.1016/j.cjca. 2014.08.016

112. Bae SM, Jung HO, Ihm SM, Kim JJ, Chin JY, Kim TS et al (2012) Hydroxychloroquine-induced cardiomyopathy that presented as pulmonary hypertension: a newly noted complication. Cardiology 123(3):197-200. https://doi.org/10.1159/000343142

113. Jankelson L, Karam G, Becker ML, Chinitz LA, Tsai MC (2020) QT prolongation, torsades de pointes, and sudden death with short courses of chloroquine or hydroxychloroquine as used in COVID19: a systematic review. Heart Rhythm. https://doi.org/10.1016/j. hrthm.2020.05.008

114. Chatre C, Roubille F, Vernhet H, Jorgensen C, Pers YM (2018) Cardiac complications attributed to chloroquine and hydroxychloroquine: a systematic review of the literature. Drug Saf 41(10):919-931. https://doi.org/10.1007/s40264-018-0689-4

115. Rosenberg ES, Dufort EM, Udo T, Wilberschied LA, Kumar J, Tesoriero J et al (2020) Association of Treatment with Hydroxychloroquine or azithromycin with in-hospital mortality in patients with COVID-19 in New York state. JAMA. https:// doi.org/10.1001/jama.2020.8630

116. Costedoat-Chalumeau N, Galicier L, Aumaître O, Francès C, Le Guern V, Lioté F et al (2013) Hydroxychloroquine in systemic lupus erythematosus: results of a French multicentre controlled trial (PLUS study). Ann Rheum Dis 72(11):1786-1792. https:// doi.org/10.1136/annrheumdis-2012-202322

117. Furst DE, Lindsley H, Baethge B, Botstein GR, Caldwell J, Dietz F et al (1999) Dose-loading with hydroxychloroquine improves the rate of response in early, active rheumatoid arthritis: a randomized, double-blind six-week trial with eighteen-week extension. 
Arthritis Rheum 42(2):357-365. https://doi.org/10.1002/15290131(199902)42:2<357::Aid-anr19>3.0.Co;2-j

118. Rothwell PM (2005) External validity of randomised controlled trials: "to whom do the results of this trial apply?". Lancet 365(9453):82-93. https://doi.org/10.1016/s0140-6736(04)17670-8
119. Ray WA (2003) Population-based studies of adverse drug effects. N Engl J Med 349(17):1592-1594. https://doi.org/10.1056/ NEJMp038145

Publisher's note Springer Nature remains neutral with regard to jurisdictional claims in published maps and institutional affiliations. 